\title{
Purification and characterization of autophagosomes from rat hepatocytes
}

\author{
Per Eivind STRØMHAUG, Trond Olav BERG, Monica FENGSRUD and Per 0. SEGLEN ${ }^{1}$ \\ Department of Cell Biology, Institute for Cancer Research, The Norwegian Radium Hospital, Montebello, N-0310 Oslo, Norway
}

To investigate the properties and intracellular origin of autophagosomes, a procedure for the purification and isolation of these organelles from rat liver has been developed. Isolated hepatocytes were incubated with vinblastine to induce autophagosome accumulation; the cells were then homogenized and treated with the cathepsin C substrate glycyl-L-phenylalanine 2naphthylamide to cause osmotic disruption of the lysosomes. Nuclei were removed by differential centrifugation, and the postnuclear supernatant was fractionated on a discontinuous Nycodenz density gradient. The autophagosomes, recognized by their content of autophagocytosed lactate dehydrogenase (LDH), could be recovered in an intermediate-density fraction, free from cytosol and mitochondria. Finally, the autophagosomes were separated from the endoplasmic reticulum and other membranous elements by centrifugation in a Percoll colloidal density gradient, followed by flotation in iodixanol to remove the Percoll particles. The final autophagosome preparation represented a 24-fold purification of autophagocytosed LDH relative to intact cells, with a $12 \%$ recovery. The purified autophagosomes contained sequestered cytoplasm with a normal ultrastructure, including mitochondria, peroxisomes and endoplasmic reticulum in the same proportions as in intact cells. However, immunoblotting indicated a relative absence of cytoskeletal elements (tubulin, actin and cytokeratin), which may evade autophagic sequestration. The autophagosomes showed no enrichment in protein markers typical of lysosomes (acid phosphatase, cathep$\sin \mathrm{B}$, lysosomal glycoprotein of $120 \mathrm{kDa}$ ), endosomes (earlyendosome-associated protein 1, cation-independent mannose 6phosphate receptor, asialoglycoprotein receptor) or endoplasmic reticulum (esterase, glucose-regulated protein of $78 \mathrm{kDa}$, protein disulphide isomerase), suggesting that the sequestering membranes are not derived directly from any of these organelles, but rather represent unique organelles (phagophores).

\section{INTRODUCTION}

Autophagy is one of the main mechanisms for the degradation of intracellular macromolecules and organelles. It plays important roles in the control of cellular protein metabolism and growth, and is subject to complex regulation by growth factors, hormones and metabolites, including feedback inhibition by amino acids [1]. Ultrastructurally, autophagy can be recognized by the presence of autophagic vacuoles inside the cells. Three types of autophagic vacuole have been identified. (1) Autophagosomes are the initial vacuoles formed when portions of cytoplasm are sequestered by single or stacked membranous cisternae, and have a characteristic morphology and biochemical composition [2-6]. (2) Amphisomes, formed by fusion of autophagosomes with endosomes, can be recognized by the colocalization of autophagic and endocytic markers in acidic vacuoles which are deficient in lysosomal markers and hydrolytic activity [6-9]. (3) Active lysosomes contain both lysosomal marker proteins and remnants of autophagocytosed cytoplasm, and usually endocytic markers as well $[6,8,10]$.

Some progress has been made in identifying signalling mechanisms involved in the control of autophagy [11-15], but nothing is known about the molecular elements directly involved in the autophagic sequestration process. Pure autophagosomes have been successfully prepared from the mouse pancreas [16], but attempts to purify autophagosomes from the rat liver have so far resulted only in 'autophagic vacuole' preparations containing a mixture of lysosomes and autophagosomes [17-19]. In the present study we have purified rat liver autophagosomes by a multi-step procedure, using osmotic disruption, differential centrifugation and density-gradient centrifugations with Nycodenz and Percoll to remove other organelles. The purified autophagosomes show no enrichment in organelle-specific marker proteins, indicating that autophagic cisternae do not derive directly from lysosomes, endosomes or the endoplasmic reticulum (ER), but rather represent unique organelles (phagophores) [3].

\section{MATERIALS AND METHODS \\ Biochemicals}

${ }^{125}$ I-Tyramine-cellobiose-asialo-orosomucoid $\quad\left({ }^{125} \mathrm{I}-\mathrm{TC}-\mathrm{AOM}\right)$ was kindly provided by Professor Trond Berg (University of Oslo, Oslo, Norway). Nycodenz, Maxidenz and iodixanol $\left(\right.$ Optiprep ${ }^{\circledR}$ ) were purchased from Nycomed Pharma AS (Oslo, Norway); Percoll was from Pharmacia AB (Uppsala, Sweden). Antibodies against $\alpha$ - and $\beta$-tubulin were from Amersham Pharmacia Biotech (Little Chalfont, Bucks., U.K.). Antibodies against protein disulphide isomerase and glucose-regulated protein of $78 \mathrm{kDa}$ (Grp78) were from Affinity BioReagents, Inc. (Golden, CO, U.S.A.). Antibodies against cathepsin B, lysosomal glycoprotein of $120 \mathrm{kDa}$ (Lgp120), cytokeratin 8, superoxide dismutase (SOD), early-endosome-associated protein 1 and the asialoglycoprotein receptor were generously donated by Dr. David Buttle (University of Sheffield Medical School, Sheffield, U.K.), Dr. William Dunn (University of Florida, Gainesville, FL, U.S.A.), Dr. Normand Marceau (Laval University, Quebec, Canada), Dr. Ling-Yi Chang (Duke University Medical Center, Durham, NC, U.S.A.), Dr. Harald Stenmark (The Norwegian Radium Hospital, Oslo, Norway), and Dr. Paul Weigel (University of Oklahoma Health Sciences Center, Oklahoma City,

Abbreviations used: ${ }^{125} \mathrm{I}-\mathrm{TC}-\mathrm{AOM},{ }^{125} \mathrm{I}$-tyramine-cellobiose-asialo-orosomucoid; 3MA, 3-methyladenine; AOM, asialo-orosomucoid; ER, endoplasmic reticulum; GPN, glycyl-L-phenylalanine 2-naphthylamide; Grp78, glucose-regulated protein of 78 kDa; HB, homogenization buffer; LDH, lactate dehydrogenase; Lgp120, Iysosomal glycoprotein of $120 \mathrm{kDa}$; SOD, superoxide dismutase; TBS, Tris-buffered saline.

1 To whom correspondence should be addressed (e-mail per.seglen@labmed.uio.no). 
OK, U.S.A.) respectively. Antibodies against $\beta$-actin and $\mathrm{p} 58$ (58 kDa Golgi protein), and all other biochemicals, including vinblastine, $p$-nitrophenyl acetate and cytochrome $c$, were obtained from Sigma Chemical Co. (St. Louis, MO, U.S.A.).

\section{Cell preparation and incubation}

Hepatocytes were prepared from $18 \mathrm{~h}$-starved male Wistar rats (250-300 g) by two-step collagenase perfusion [20]. The hepatocytes from one liver (about $3.6 \mathrm{~g}$ cellular wet mass, corresponding to one-third of the liver mass) were suspended in suspension buffer [20] fortified with pyruvate $(20 \mathrm{mM})$ and $\mathrm{Mg}^{2+}(2 \mathrm{mM})$, to a final volume of $48 \mathrm{ml}$. The cells were distributed as $0.4 \mathrm{ml}$ aliquots $(70-90 \mathrm{mg}$ wet $\mathrm{wt} . / \mathrm{ml})$ in 120 centrifuge tubes and incubated, with shaking, at $37^{\circ} \mathrm{C}$ for $2 \mathrm{~h}$, usually in the presence of $50 \mu \mathrm{M}$ vinblastine to induce autophagosome accumulation [21]. In some experiments, a trace amount of ${ }^{125} \mathrm{I}-\mathrm{TC}-\mathrm{AOM}$ along with $200 \mathrm{nM}$ AOM or $200 \mathrm{nM}$ AOM-gold (3 nm or $10 \mathrm{~nm}$ diameter), or $200 \mathrm{nM}$ AOM-gold alone, was included as an endocytic marker [22].

\section{Cell disruption and measurement of autophagocytosed lactate dehydrogenase (LDH)}

After incubation, the cells were washed twice in $10 \%(\mathrm{w} / \mathrm{v})$ unbuffered, electrolyte-free sucrose, resuspended in $10 \%(\mathrm{w} / \mathrm{v})$ unbuffered sucrose to the original volume $(48 \mathrm{ml})$, and electrodisrupted (as $3 \mathrm{ml}$ aliquots) by a single high-voltage pulse [23]. For autophagy measurements, the disruptates were centrifuged $(3700 \mathrm{~g} ; 30 \mathrm{~min})$ through a Metrizamide cushion, and the amount of autophagically sequestered LDH in the cytosol-free cell corpse sediment was measured and expressed as a percentage of the total cellular LDH in the disruptate [24].

\section{Subcellular fractionation}

For subcellular fractionation, $48 \mathrm{ml}$ of cell disruptate (in $10 \%$ sucrose) was mixed with $0.5 \mathrm{ml}$ of a buffer concentrate $(1 \mathrm{M}$ Hepes/0.1 M EDTA) and homogenized by 10 strokes in a Dounce homogenizer with a tightly fitting pestle. This homogenate was diluted with $24 \mathrm{ml}$ of homogenization buffer (HB; $0.25 \mathrm{M}$ sucrose, $10 \mathrm{mM}$ Hepes, $1 \mathrm{mM}$ EDTA, pH 7.3) containing $1.5 \mathrm{mM}$ glycyl-L-phenylalanine 2-naphthylamide (GPN) and $1 \%$ DMSO, to a final GPN concentration of $0.5 \mathrm{mM}$ and a final homogenate concentration of $5 \%$. After incubation for $6 \mathrm{~min}$ at $37{ }^{\circ} \mathrm{C}$ to destroy the lysosomes [21,25], the homogenate was cooled to $4{ }^{\circ} \mathrm{C}$, and the rest of the procedure was performed at this temperature. Four tubes each containing $18 \mathrm{ml}$ of GPNtreated homogenate were centrifuged at $2000 \mathrm{~g}$ (4000 rev./min) in an SS-34 rotor (Sorvall) for $2 \mathrm{~min}$ to obtain a nuclear pellet and a supernatant. The nuclear pellets were washed once in $4 \mathrm{ml}$ of $\mathrm{HB}$, and the supernatants $(16 \mathrm{ml})$ were combined with the previous one $(72 \mathrm{ml})$ to give a single postnuclear supernatant. A $14 \mathrm{ml}$ aliquot of this postnuclear supernatant was placed on top of a discontinuous (two-step) Nycodenz gradient (i.e. six gradients altogether), prepared by diluting isotonic $(36 \%$ $\mathrm{w} / \mathrm{v})$ Nycodenz with $\mathrm{HB}$ to obtain a top layer of $17 \mathrm{ml}$ of $9.5 \%$ Nycodenz $(1.072 \mathrm{~g} / \mathrm{ml})$ and a bottom layer of $7 \mathrm{ml}$ of $22.5 \%$ Nycodenz $(1.127 \mathrm{~g} / \mathrm{ml})$. The Nycodenz gradient was centrifuged for $1 \mathrm{~h}$ at $141000 \mathrm{~g}$ (28000 rev./min) in an SW28 rotor (Beckman ultracentrifuge), and divided into three fractions by aspiration: a light fraction (upper; $\approx 28 \mathrm{ml}$ ), an interface band $(5 \mathrm{ml})$ and a heavy fraction (the pellet, mostly mitochondria, resuspended in the final $5 \mathrm{ml}$ of the bottom layer). The interface band, which contained the autophagosomes, was diluted with $5 \mathrm{ml}$ of $\mathrm{HB}$ and layered on top of a discontinuous gradient of
$21 \mathrm{ml}$ of $33 \%$ Percoll in HB on top of $7 \mathrm{ml}$ of $22.5 \%$ Nycodenz in $\mathrm{HB}(1.127 \mathrm{~g} / \mathrm{ml})$, and centrifuged for $30 \mathrm{~min}$ at $72000 \mathrm{~g}$ (20000 rev./min) in the SW28 rotor. The autophagosomes banded at the lower interface, and were, for preparative purposes, recovered by aspiration (Pasteur pipette) in a volume of about $5 \mathrm{ml}$. The ER banded at the upper interface, from which it could be recovered for analysis if necessary. For analytical purposes, the gradient was divided into $2.5 \mathrm{ml}$ fractions by upward displacement using Maxidenz as displacement fluid. Percoll was removed from the fractions of interest (e.g. the autophagosomes) by mixing $5 \mathrm{ml}$ of the fraction with $3.5 \mathrm{ml}$ of isotonic $60 \%(\mathrm{w} / \mathrm{v})$ iodixanol in water, overlaying with $1.5 \mathrm{ml}$ of $30 \%$ iodixanol and a top layer of $2.5 \mathrm{ml}$ of $\mathrm{HB}$, and centrifuging for $30 \mathrm{~min}$ in an SW40 rotor (Beckman ultracentrifuge) at $71000 \mathrm{~g}$ (20000 rev./min). The Percoll particles (colloidal silica) sedimented to the bottom of the tube, whereas the autophagosome band forming by flotation at the iodixanol/HB interface could be recovered by aspiration or upward displacement. The autophagosome purification scheme is outlined in Scheme 1.

Purified lysosomes were prepared by the scheme described above, except that the hepatocytes were preincubated for $2 \mathrm{~h}$ at $37^{\circ} \mathrm{C}$ with $10 \mathrm{mM} 3$-methyladenine (3MA) rather than with vinblastine, and the GPN step was omitted.

Cytosol was prepared separately by centrifugation of a cell homogenate for $1 \mathrm{~h}$ at $20000 \mathrm{rev} . / \mathrm{min}(50000 \mathrm{~g})$ in the Sorvall SS-34 rotor.

\section{Assays and analyses}

Enzymes and protein were determined spectrophotometrically in a Technicon RA-1000 autoanalyser. LDH [26] and acid phosphatase [27] were measured by the use of kits for automated analysis from Boehringer Mannheim (Mannheim, Germany); protein was measured with a kit from Bio-Rad (Munich, Germany). Cytochrome $c$ oxidase was measured by the method of Cooperstein and Lazarow [28], and neutral esterase was measured by the hydrolysis of $p$-nitrophenyl acetate according to Beaufay et al. [29]. Radioactivity was measured in a 1261 Multigamma counter from LKB Wallac Oy (Oulu, Finland). Recoveries of the organelle markers were expressed as percentages of the total values in the initial cell homogenate. The recovery of autophagocytosed $\mathrm{LDH}$ was determined by subtracting the amount of LDH found in parallel fractions from cells incubated in the presence of the autophagy inhibitor 3MA [30] at $10 \mathrm{mM}$, and was expressed as a percentage of the 3MAsensitive LDH sequestration in whole cells, measured separately in the same experiment. The degree of purification was calculated as the ratio between marker recovery and total protein recovery in the same preparation.

\section{Immunoblotting (Western blotting)}

For immunoblotting of enzymic markers in the various organelle preparations, an initial protein separation was performed by one-dimensional SDS/PAGE, using the mini-Protean equipment from Bio-Rad. The separated proteins were then transferred on to Nitropure nitrocellulose supports (Micron Separations Inc., West Borough, MA, U.S.A.) using a Bio-Rad Semi-dry Transblot apparatus. The blots were blocked overnight in $5 \%(\mathrm{w} / \mathrm{v})$ nonfat dried milk in Tris-buffered saline (TBS; $25 \mathrm{mM}$ Tris, $0.8 \%$ $\mathrm{NaCl}, \mathrm{pH}$ 7.4), and then incubated at room temperature for $2 \mathrm{~h}$ with primary antibody and for $30 \mathrm{~min}$ with horseradish peroxidase-conjugated secondary antibody (both in TBS/2\% dried milk); after each step, the blots were washed three times in TBS $/ 0.1 \%$ Tween 20 . The antibodies were detected by chemi- 

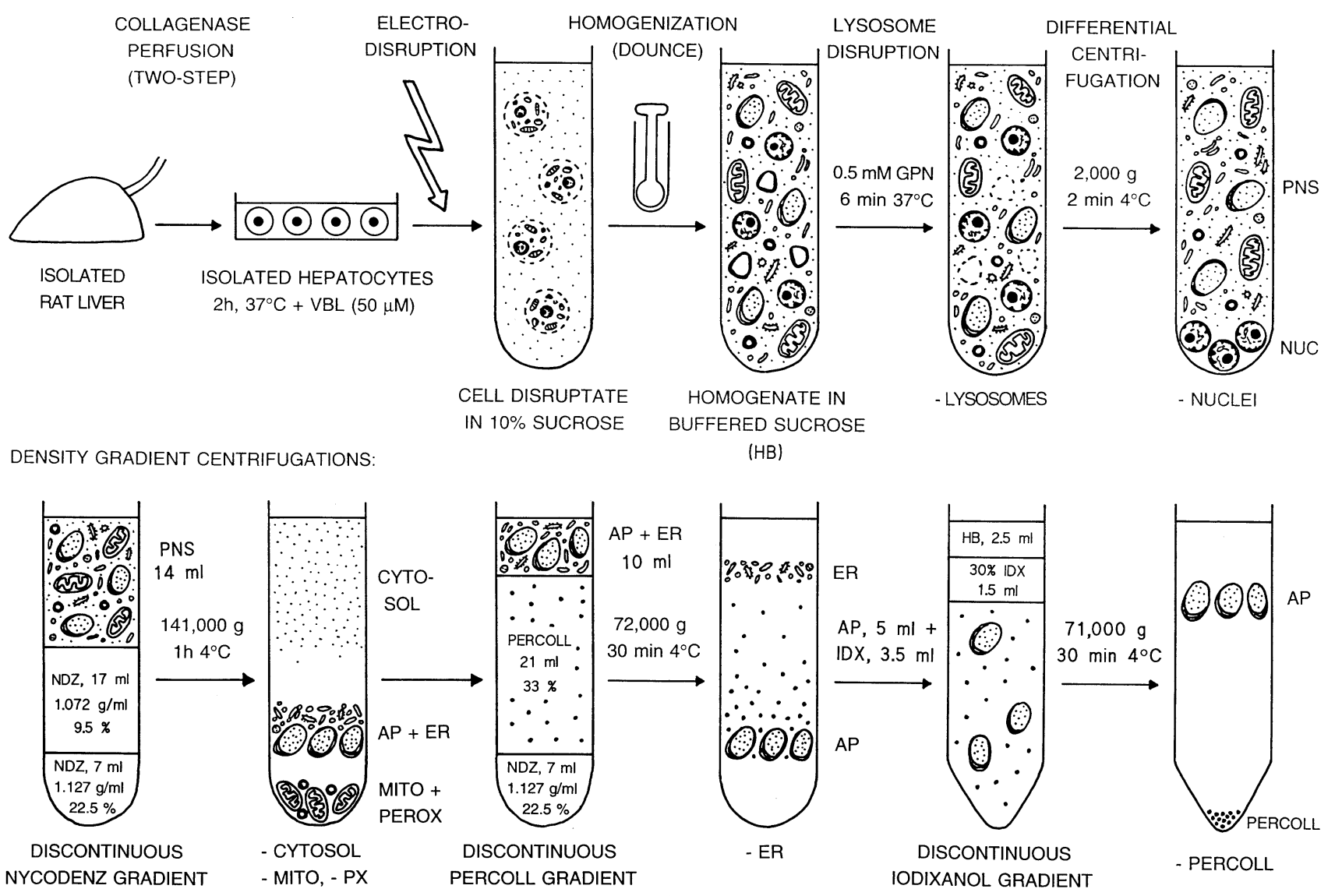

\section{Scheme 1 Scheme for purification of rat liver autophagosomes}

Details are given in the Materials and methods section. Abbreviations: AP, autophagosomes; ER, endoplasmic reticulum-enriched membrane fraction; HB, homogenization buffer; IDX, iodixanol; MITO, mitochondria; NDZ, nycodenz; NUC, nuclei; PNS, postnuclear supematant; PX/PEROX, peroxisomes; VBL, vinblastine.

luminescence, using the SuperSignal peroxidase substrate (Pierce, Rockford, IL, U.S.A.) and Kodak X-Omat LS film (Kodak, New Haven, CT, U.S.A.). The films were digitalized with a model 300A laser densitometer from Molecular Dynamics Inc. (Sunnyvale, CA, U.S.A.).

\section{Electron microscopy}

Cells and fractions were fixed in $4 \%(\mathrm{w} / \mathrm{v})$ glutaraldehyde $/ 0.1 \mathrm{M}$ cacodylate buffer $/ 4 \%(\mathrm{w} / \mathrm{v})$ sucrose overnight at $4{ }^{\circ} \mathrm{C}$. The fixed fractions were pelleted in $1.5 \mathrm{ml}$ Eppendorf tubes by centrifugation for $45 \mathrm{~min}$ at $13000 \mathrm{rev} . / \mathrm{min}(13000 \mathrm{~g})$ in a HeraeusChrist Biofuge A table centrifuge, and post-fixed for $60 \mathrm{~min}$ in $1 \%(\mathrm{w} / \mathrm{v}) \mathrm{OsO}_{4}$ reduced with $1.5 \%(\mathrm{w} / \mathrm{v})$ potassium ferrocyanide, followed by en bloc staining with $1.5 \%$ (w/v) uranyl acetate. After serial dehydration in ethanol and propylene oxide, specimens were embedded in Epon. The pelleted fractions were turned $90^{\circ}$ before sectioning. The sections were post-stained with $0.2 \%(\mathrm{w} / \mathrm{v})$ lead citrate, and examined in a Philips CM10 electron microscope at $60 \mathrm{kV}$.

The number of autophagosome profiles per cell profile, as well as the quantitative composition of the autophagosomal contents, were recorded by examination, at $10500 \times$ magnification, of randomly selected cell profiles (with a nucleus) or autophagosome profiles in sections from three independent experiments. In the contents analysis of purified autophagosomes, profiles from all levels of the pellet were examined to avoid any bias.

The numbers of endosomes and amphisomes in the autophagosome preparation were determined by examination, at $13500 \times$ magnification, of sections from an experiment where AOM-gold had been included as an endocytic marker during the incubation of the cells. The AOM-gold was prepared by adding desialylated orosomucoid to gold particles, as described by Slot and Geuze [31].

\section{RESULTS AND DISCUSSION}

\section{Vinblastine-induced accumulation of autophagosomes}

In order to optimize the yield of purified autophagosomes, isolated rat hepatocytes were incubated at $37^{\circ} \mathrm{C}$ in an amino acid-free medium to ensure a maximal rate of autophagy [32], and in the presence of vinblastine to induce autophagosome accumulation [33]. After $2 \mathrm{~h}$ of incubation, the number of ultrastructurally identifiable autophagosomes per cell had increased 6-7-fold, and the amount of autophagocytosed, 3MAsensitive [30] LDH had increased approx. 9-fold. Since the autophagosomal LDH is sedimentable, and thus easily separated from cytosolic LDH during organelle purification, we have used 


\section{Table 1 Characterization of the purification steps leading to purified autophagosomes and lysosomes}

Isolated rat hepatocytes were incubated for $2 \mathrm{~h}$ at $37^{\circ} \mathrm{C}$ with $50 \mu \mathrm{M}$ vinblastine or with $50 \mu \mathrm{M}$ vinblastine $+10 \mathrm{mM} 3 \mathrm{MA}$. Cell homogenates were either mock-incubated or incubated with $0.5 \mathrm{mM}$ GPN for 6 min at $37^{\circ} \mathrm{C}$ and fractionated as described in the Materials and methods section. The fractions in lines $1-7$ represent cells incubated with vinblastine and treated with GPN, while the bottom line ('Lysosomes') represents cells incubated with vinblastine + 3MA and not treated with GPN. Organelle marker recoveries are expressed as percentages of the total values in cell homogenates. Autophagocytosed LDH represents 3MA-sensitive LDH as a percentage of total LDH in the cell. Each value is the mean \pm S.E.M. of seven independent experiments. Purif. $=$ degree of purification (marker recovery/protein recovery).

Recovery of organelle marker (\% of total in cell homogenate) and degree of marker purification (relative to total cell homogenate)

\begin{tabular}{|c|c|c|c|c|c|c|c|c|c|c|c|c|c|}
\hline \multirow[b]{2}{*}{ Cell fraction } & \multirow{2}{*}{$\begin{array}{l}\text { Protein } \\
\text { recovery }\end{array}$} & \multicolumn{2}{|l|}{ Total LDH } & \multicolumn{2}{|c|}{ Autophagocytosed LDH } & \multicolumn{2}{|c|}{ Acid phosphatase } & \multicolumn{2}{|c|}{ Neutral esterase } & \multicolumn{2}{|c|}{ Cytochrome $c$ oxidase } & \multicolumn{2}{|l|}{${ }^{125}$-TC-AOM } \\
\hline & & Recovery & Purif. & Recovery & Purif. & Recovery & Purif. & Recovery & Purif. & Recovery & Purif. & Recovery & Purif. \\
\hline Cell homogenate & 100 & 100 & 1.0 & 100 & 1.0 & 100 & 1.0 & 100 & 1.0 & 100 & 1.0 & 100 & 1.0 \\
\hline Postnuclear supernatant & $74.6 \pm 4.9$ & $94.7 \pm 2.5$ & 1.3 & & & $93.7 \pm 4.1$ & 1.3 & $91.4 \pm 5.6$ & 1.2 & $85.0 \pm 5.8$ & 1.1 & $82.9 \pm 3.9$ & 1.1 \\
\hline Nuclear fraction & $14.2 \pm 2.9$ & $4.5 \pm 0.5$ & 0.3 & & & $5.3 \pm 1.5$ & 0.4 & $8.0 \pm 2.0$ & 0.6 & $13.6 \pm 3.9$ & 1.0 & $6.8 \pm 1.9$ & 0.5 \\
\hline Nycodenz light fraction & $48.9 \pm 4.3$ & $90.4 \pm 5.7$ & 1.8 & & & $74.6 \pm 3.6$ & 1.5 & $46.4 \pm 3.1$ & 0.9 & $1.3 \pm 0.5$ & 0.03 & $39.6 \pm 3.7$ & 0.8 \\
\hline Nycodenz heavy fraction & $27.5 \pm 2.3$ & $1.0 \pm 0.1$ & 0.04 & & & $5.3 \pm 0.6$ & 0.2 & $21.4 \pm 2.8$ & 0.8 & $78.1 \pm 5.9$ & 2.8 & $4.0 \pm 0.8$ & 0.1 \\
\hline Nycodenz interface band & $10.3 \pm 1.1$ & $3.8 \pm 0.2$ & 0.4 & $32.3 \pm 2.6$ & 3.1 & $15.4 \pm 0.8$ & 1.5 & $31.7 \pm 2.0$ & 3.1 & $2.1 \pm 0.3$ & 0.2 & $28.9 \pm 1.4$ & 2.8 \\
\hline Autophagosomes & $0.5 \pm 0.1$ & $0.4 \pm 0.0$ & 0.8 & $11.8 \pm 0.8$ & 23.6 & $0.8 \pm 0.1$ & 1.6 & $0.7 \pm 0.1$ & 1.4 & $0.4 \pm 0.1$ & 0.8 & $2.6 \pm 0.5$ & 5.2 \\
\hline Lysosomes & $0.3 \pm 0.0$ & $0.1 \pm 0.0$ & 0.3 & & & $10.4 \pm 0.6$ & 34.7 & $0.4 \pm 0.1$ & 1.3 & $0.2 \pm 0.1$ & 0.7 & $2.6 \pm 0.8$ & 8.7 \\
\hline
\end{tabular}

this enzyme as an autophagosome marker during the development of the autophagosome purification procedure.

\section{Removal of lysosomes by osmotic disruption}

Since hepatic autophagosomes and lysosomes are too similar in density to be separated by density-gradient methods [18,21], we chose to remove the lysosomes by selective disruption. This can be done by in vivo loading of the lysosomes with a photoactivatable porphyrin [34], a method suitable for targeted disruption of lysosomes in intact cells, or by osmotic lysis of the lysosomes in cell homogenates by the cathepsin C substrate GPN $[21,25]$, which is a more convenient method for preparative purposes. A brief treatment of the homogenate with GPN greatly decreased the recovery of the lysosomal marker enzyme, acid phosphatase, in subsequently isolated autophagosome-enriched fractions (see below), without significantly affecting the recoveries of other organelle markers (results not shown).

\section{Removal of mitochondria and cytosol by discontinuous Nycodenz density-gradient centrifugation}

After the GPN treatment, the hepatocyte homogenates were centrifuged at low speed to remove nuclei. To remove mitochondria and cytosol, which in isotonic Nycodenz density gradients are denser and lighter respectively than autophagosomes [21], the postnuclear supernatant was layered on top of two Nycodenz layers of different densities. After centrifugation for $1 \mathrm{~h}$, mitochondria (and peroxisomes) had sedimented to the bottom of the tube ('Nycodenz heavy fraction'), and the cytosol remained above the light Nycodenz layer ('Nycodenz light fraction'), whereas autophagosomes and membranous material banded at the interface between the two Nycodenz layers ('Nycodenz interface band'). As shown in Table 1, the interface band, representing about $10 \%$ of the cellular protein, contained one-third of the autophagosomes (autophagocytosed LDH), but only $2 \%$ of the mitochondria (cytochrome $c$ oxidase), half of which were apparently inside autophagosomes, as indicated by the 3MA-sensitivity of their marker enzyme activity (results not shown). There was also very little cytosolic contamination of the interface band $(4 \%$ of the cellular $\mathrm{LDH}$, one-quarter of which appeared to be inside autophagosomes). In addition to the autophagosomes, the interface band contained one-third of the endosomes (endocytosed AOM) and one-third of the ER (neutral esterase) (Table 1).

\section{Removal of ER by Percoll gradient centrifugation}

Although the microsomes formed from the ER and other cytomembranes upon homogenization are smaller than autophagosomes, we were unable to remove them satisfactorily by differential centrifugation, and they overlapped with the autophagosomes in both sucrose and Nycodenz density gradients (results not shown). However, since initial trials indicated that ER and autophagosomes could be separated on Percoll density gradients, we layered the diluted Nycodenz interface band on top of $33 \%(\mathrm{w} / \mathrm{v})$ Percoll, with a bottom cushion of dense Nycodenz. After a $30 \mathrm{~min}$ centrifugation, the autophagosomes (3MAsensitive LDH) had moved to the bottom of the Percoll layer (Figure 1A), whereas most of the protein (Figure 1F), including nearly all of the ER (neutral esterase activity; Figure 1C) and cytosol (3MA-resistant LDH; Figure 1A), remained on top. About half of the AOM failed to enter the Percoll, but a significant fraction of this endocytic marker still banded with the autophagosomes, and was 3MA-resistant (Figure 1D), indicating incomplete removal of endosomes. Figure 1 includes results with homogenates not subjected to GPN treatment, illustrating the effectiveness of this step in removing lysosomes (Figure 1B) without affecting the autophagosomes (Figure 1A) or other organelles.

Since the silica particles in Percoll interfered with subsequent enzyme assays and electron microscopy studies, they were removed by centrifugation in iodixanol, a substance that can form isotonic solutions of sufficient density to float the autophagosomes while allowing sedimentation of the silica particles. Autophagosomes recovered after flotation in iodixanol appeared morphologically as a highly pure and homogeneous preparation, with excellent preservation of ultrastructural detail (Figure 2).

\section{Enzymic and morphological characterization of purified autophagosomes}

In the final autophagosome preparation, which contained $0.5 \%$ of the cellular protein, about $12 \%$ of the autophagocytosed 


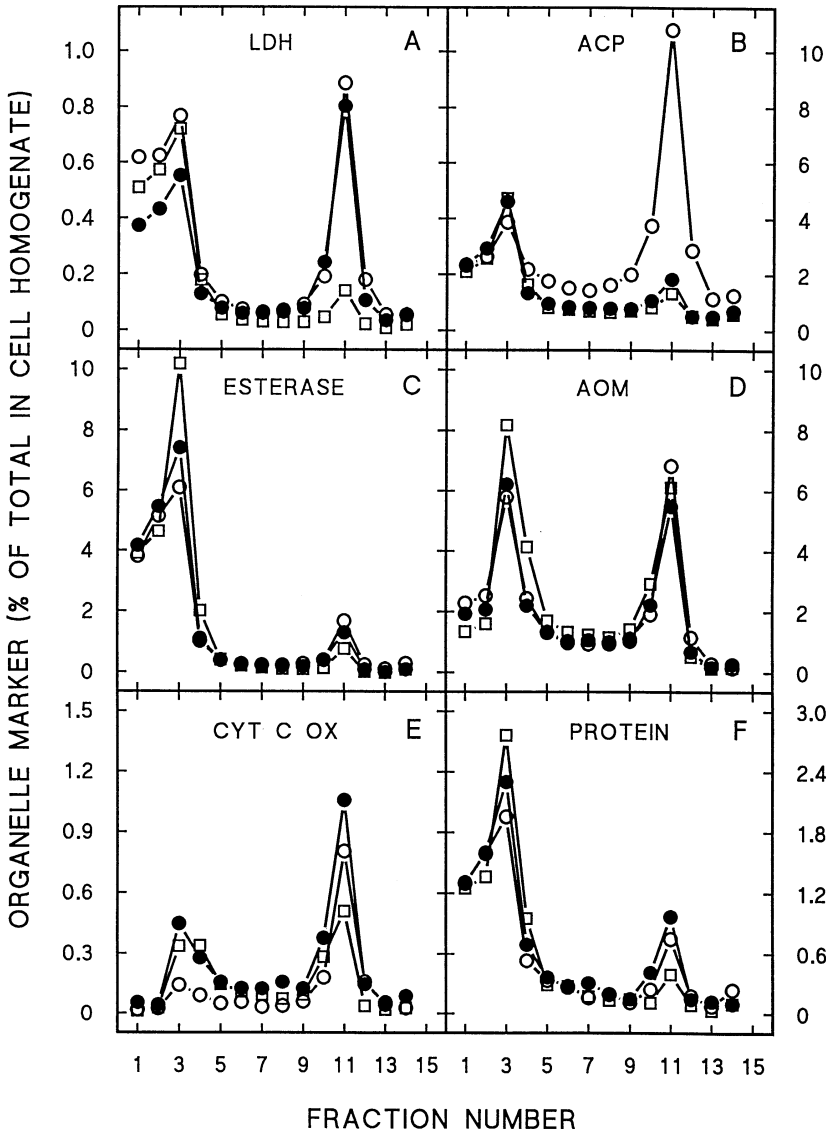

Figure 1 Distribution of enzyme markers in Percoll gradients

Hepatocytes incubated with $50 \mu \mathrm{M}$ vinblastine $(\bigcirc, \mathbf{O})$ or with a combination of $50 \mu \mathrm{M}$ vinblastine plus $10 \mathrm{mM} 3 \mathrm{MA}(\square)$ for $2 \mathrm{~h}$ at $37^{\circ} \mathrm{C}$ were electrodisrupted and homogenized. The homogenates were incubated for 6 min at $37^{\circ} \mathrm{C}$ without additions $(\mathrm{O})$ or with $0.5 \mathrm{mM}$ GPN $(\boldsymbol{O}, \square)$. Interface Nycodenz bands were recovered as described in the Materials and methods section and layered on top of discontinuous Percoll/Nycodenz gradients. Following centrifugation, the gradients were divided into 14 fractions of $2.5 \mathrm{ml}$ each. $\mathrm{LDH}(\mathbf{A})$, acid phosphatase $(\mathbf{B})$, esterase $(\mathbf{C}),{ }^{125}$-TC-AOM $(\mathbf{D})$, cytochrome $c$ oxidase $(\mathbf{E})$ and protein $(\mathbf{F})$ were measured in the fractions, and amounts are expressed relative to the corresponding total amounts in the homogenate.

LDH was recovered relative to the initial cell homogenate (Table 1). This represents a 24 -fold purification, which may be close to the maximal degree of purification obtainable, given the high content of cytoplasmic protein in these organelles (cf. also their high morphological purity; Figure 2).

The autophagosome preparation was somewhat enriched in the endocytic marker protein AOM (Table 1). A morphometric analysis of organelles labelled with AOM-conjugated gold particles, endocytosed by the cells for $2 \mathrm{~h}$ prior to organelle purification [14], revealed that about 5\% (by number) of the vacuoles in the preparation were endosomes. Gold-labelled endosomes were occasionally included in autophagosomes as part of the sequestered cytoplasm (Figure 3A), but most of the endosomes were free, of the multivesicular type (Figures $3 \mathrm{E}-3 \mathrm{G}$ ). Gold particles were also associated with small endocytic vesicles (Figure $3 \mathrm{H}$ ) or complex tubulovesicular structures probably corresponding to early endosomes (Figure 3I). Gold-labelled endocytic elements were frequently observed in the membrane fraction isolated by Percoll gradient centrifugation (Figure 3J), suggesting that most of the endosomes were removed at this step.

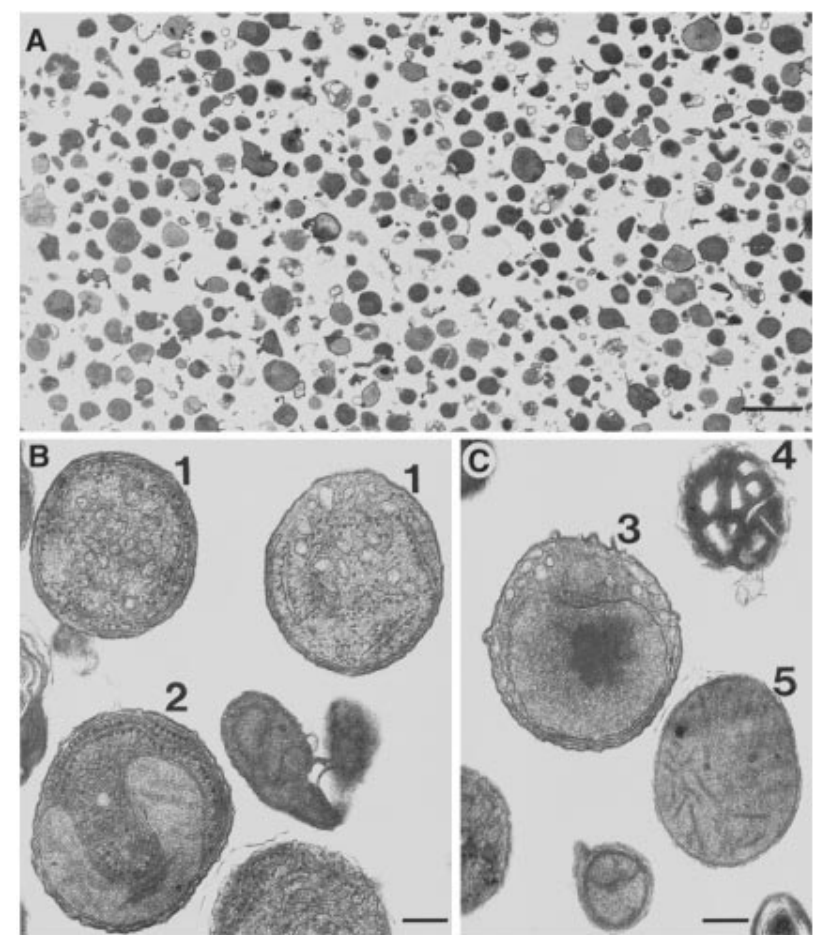

\section{Figure 2 Ultrastructure of purified autophagosomes}

Isolated autophagosomes were prepared for conventional electron microscopy as described in the Materials and methods section. (A) Low-power overview. Bar $=2 \mu \mathrm{m}$. (B, C) Autophagosomes containing well preserved ER $(1,2)$, peroxisomes (3) and mitochondria $(2,5)$, in contrast with the damaged mitochondria occasionally observed outside autophagosomes (4). Bar $=200 \mathrm{~nm}$

Since endosomes are much smaller than autophagosomes, their role as a contaminant in the autophagosome preparation could be regarded as negligible (less than $0.4 \%$ by mass).

About $5 \%$ of the vacuoles in the autophagosome preparation were amphisomes [6,7], which could be recognized by the presence of normal cytoplasm and AOM-gold particles within the same vacuole, usually in separate areas (Figures 3B-3D).

Marker enzymes for lysosomes (acid phosphatase), ER (neutral esterase), mitochondria (cytochrome $c$ oxidase) and cytosol (total LDH) showed recoveries of only $0.4-0.8 \%$ in the autophagosome preparation. The specific activities were similar to the homogenate values, as would be expected of autophagosomes containing randomly sequestered cytoplasm. The cytoplasmic content of the isolated autophagosomes had the same organelle composition as in autophagosomes in situ, with peroxisomes in $4 \%$, mitochondria in about $30 \%$, and rough ER in about $70 \%$ of the autophagosomes (results not shown), indicating that a representative sample of autophagosomes had been isolated. The excellent ultrastructural preservation made it easy to distinguish, for example, the normal-looking mitochondria inside autophagosomes from the swollen and vacuolated free mitochondria occasionally contaminating the preparation (Figure 2C).

\section{Purification and characterization of lysosomes}

Our purification scheme could be switched from the purification of autophagosomes to that of lysosomes simply by incubating 


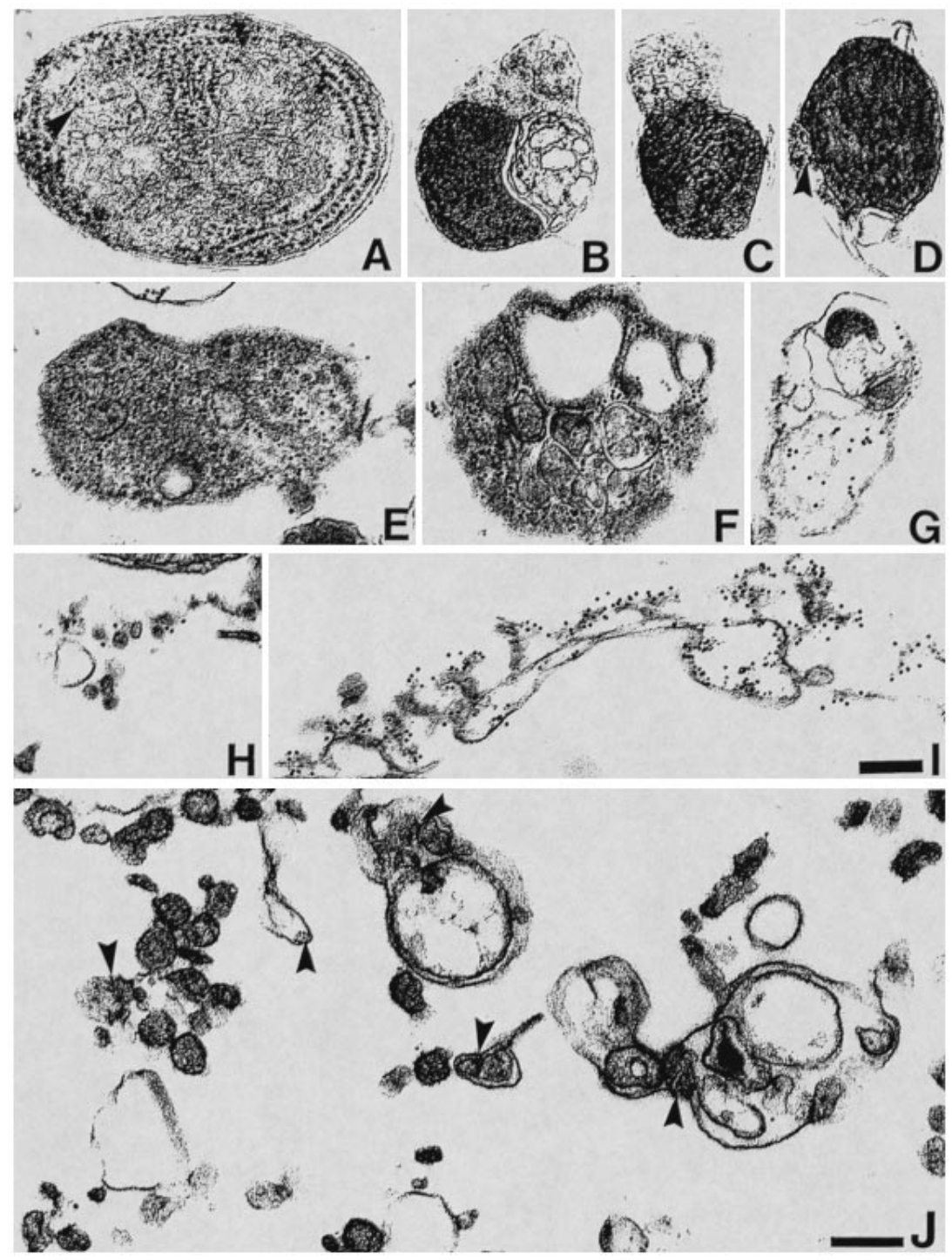

Figure 3 Localization of endocytosed AOM-gold in the autophagosome and membrane preparations

In autophagosome preparations, prepared for conventional electron microscopy from hepatocytes incubated for $2 \mathrm{~h}$ at $37^{\circ} \mathrm{C}$ with $10 \mathrm{~nm}(\mathbf{A}-\mathbf{I})$ or $3 \mathrm{~nm}(\mathbf{J})$ A0M-gold, gold particles (arrowheads) can be found in endosomes sequestered inside autophagosomes $(\mathbf{A})$, in amphisomes $(\mathbf{B}-\mathbf{D})$, in large, multivesicular endosomes $(\mathbf{E}-\mathbf{G})$, in small endocytic vesicles $(\mathbf{H})$ and in complex tubulovesicular endosomes (I). Membrane preparations from the Percoll step contain many partly fragmented endosomes labelled with AOM-gold $(\mathbf{J})$. Bar $=200 \mathrm{~nm}$.

the hepatocytes with 3MA (to suppress autophagy) rather than with vinblastine, and by omitting the GPN step. As shown in Table 1 (last line), the result was a preparation of highly purified lysosomes $(10 \%$ recovery; 40 -fold purification of acid phosphatase). The lysosomes were slightly contaminated with endosomes (to the same extent as the autophagosome preparation), but essentially devoid of other marker enzymes. Figure 4(A) shows that organelles prepared without GPN and 3MA treatment were a mixture of autophagosomes and large, morphologically heterogeneous lysosomes, in contrast with the pure autophagosome preparation obtained with GPN (Figure 4B). Pure lysosomes, prepared without GPN treatment but from 3MA-treated cells (Figure 4C), were smaller and more homogeneous, and contained less material of identifiable autophagic origin. After treatment with both 3MA and GPN, very few vacuoles were recovered; these looked like miniature auto- phagosomes (Figure 4D), and could be the result of residual, 3MA-resistant 'background' autophagy.

\section{Characterization of purified autophagosomes and lysosomes by immunoblotting}

Various subcellular fractions were characterized by immunoblotting (Western blotting), using specific antibodies against potential organelle markers. The lysosomal proteinase cathepsin B (Figure 5A) and the lysosomal membrane protein Lgp120 (Figure 5B) were highly enriched (more than 35-fold, as determined by laser densitometry) in lysosomal preparations, but were only faintly detectable in the autophagosomes, ruling out lysosomes as an immediate source of membranes for the autophagic sequestration process. The cytosolic enzyme SOD is 


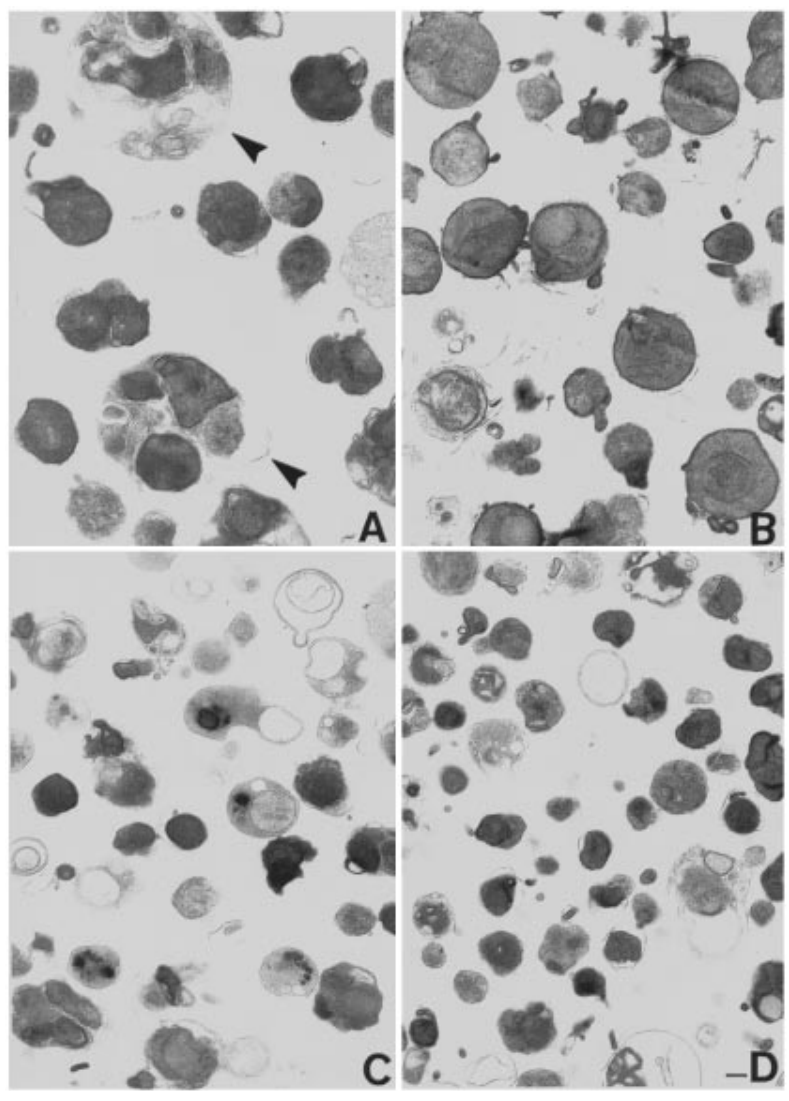

Figure 4 Effects of 3MA and GPN pretreatments on the composition of the final vacuole preparation

Hepatocytes were incubated for $2 \mathrm{~h}$ at $37^{\circ} \mathrm{C}$ with vinblastine $(50 \mu \mathrm{M})$, with or without $3 \mathrm{MA}$ $(10 \mathrm{mM})$ as indicated below. Autophagic vacuoles were prepared as described in the Materials and methods section, with or without GPN treatment of the homogenate. (A) No 3MA or GPN: autophagosomes as well as typical lysosomes (arrowheads) are seen. (B) GPN only: an essentially pure autophagosome preparation has been obtained. (C) 3MA only: dark lysosomes (residual bodies) as well as small autophagosome-like vacuoles are seen. (D) 3MA plus GPN: only debris and small autophagosome-like vacuoles are present. Bar $=200 \mathrm{~nm}$.

relatively degradation-resistant [10], and was, accordingly, present at equal levels in lysosomes and autophagosomes, as well as in the cytosol (Figure 5C). The $58 \mathrm{kDa}$ Golgi-associated microtubule-binding protein [35] was enriched in the cytosol rather than in the membrane fraction (Figure 5D), suggesting that it had detached from the Golgi during homogenization to become a cytosolic marker. This $58 \mathrm{kDa}$ protein was sequestered into autophagosomes but, unlike SOD, it was apparently degraded in the lysosomes.

Protein disulphide isomerase, a $\mathrm{Ca}^{2+}$-binding protein associated with the luminal surface of ER membranes as well as with the plasma membrane [36], was highly enriched in the membrane preparation, where it was evident as two separate bands (Figure $5 \mathrm{E}$ ). Some protein disulphide isomerase was in fact present in all fractions, as was the luminal ER protein Grp78 (Figure 5F), illustrating the problem of preparing organelles free from ER contamination. However, none of these ER marker proteins were enriched in the autophagosome fraction, indicating that neither the ER nor the plasma membrane are directly responsible for autophagosome formation. Although some studies have reported the presence of ER marker proteins in sequestering membranes and in the walls of autophagosomes [37-39], other
(A) Cathepsin B

(B) Lgp120

(C) SOD

(D) Golgi $58 \mathrm{kDa}$

(E) PDI

(F) Grp78

(G) $\alpha+\beta-$ Tubulin

(H) $\beta$-Actin

(I) Cytokeratin 8 (CK55)
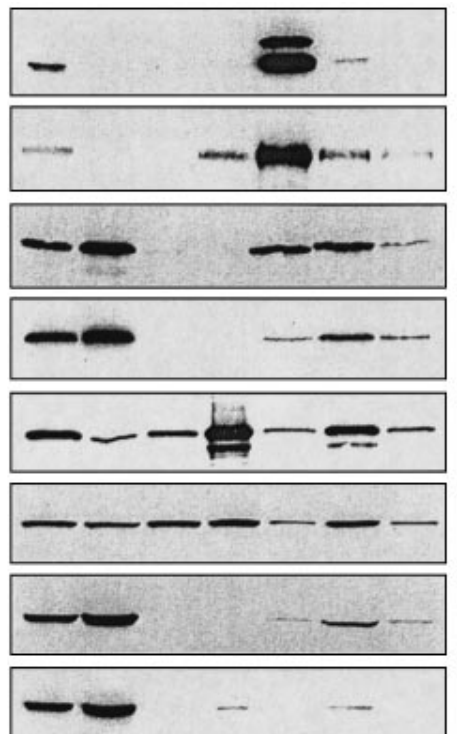

$-$
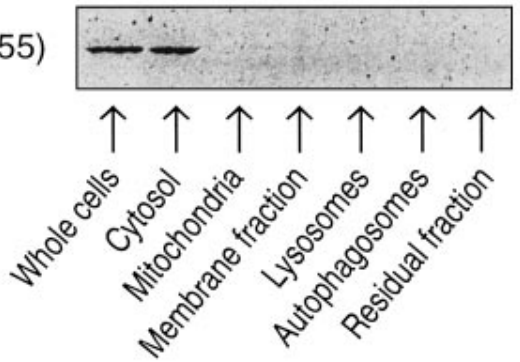

Figure 5 Immunoblotting of organelle marker enzymes in various subcellular preparations

Proteins from various subcellular fractions were separated by SDS/PAGE, electroblotted on to nitrocellulose, and probed with antibodies. Equal amounts of protein were loaded in each lane, except for lanes 5 and 7 , where a fraction volume equivalent to the autophagosomes was loaded. Lanes (from left to right): lane 1, total cell protein; lane 2, cytosol (from a homogenate centrifuged at $50000 \boldsymbol{g}$ for $60 \mathrm{~min}$ ); lane 3, crude mitochondrial fraction (heavy Nycodenz fraction); lane 4, membranous fraction (fraction no. 3 from a Percoll gradient); lane 5, purified lysosomes; lane 6, purified autophagosomes; lane 7, residual, 3MA-resistant fraction. PDI, protein disulphide isomerase.

studies have found that autophagosomes lack ER markers $[2,5,40-43]$, and that autophagic sequestration can proceed in the absence of a functional ER [44]. The weight of the evidence thus suggests that, even if the sequestering membranes ultimately derive from ER cisternae (as do all cytomembranes), they must be so highly modified as to warrant their proposed status as distinct organelles, i.e. phagophores [3].

The cation-independent mannose 6-phosphate receptor is a marker protein of Golgi membranes and late endosomes which has also been reported to be present in the delimiting membranes of early autophagic vacuoles in situ [8]. However, immunoblotting revealed that isolated autophagosomes were virtually devoid of the mannose 6-phosphate receptor, as well as of two other endosomal marker proteins, early-endosome-associated protein 1 [45] and the asialoglycoprotein receptor [46] (results not shown). Endosomes, and probably Golgi cisternae as well, can, therefore, most probably be excluded as sources of membrane for the autophagic sequestration process. The presence of endosomal markers in early autophagic vacuoles in situ [8] would in fact 
suggest these vacuoles to be amphisomes, which are positive for these markers [47], rather than autophagosomes.

\section{Relative exclusion of cytoskeletal elements from autophagosomes}

Antibodies against $\alpha$-and $\beta$-tubulin (Figure $5 \mathrm{G}$ ), $\beta$-actin (Figure $5 \mathrm{H}$ ) and $55 \mathrm{kDa}$ cytokeratin 8 (Figure $5 \mathrm{I}$ ) gave strong immunostaining in the cytosol fraction, suggesting that these cytoskeletal proteins, which form well-organized networks in intact cells [48], become extensively solubilized during the cell homogenization procedure. In the autophagosomes, on the other hand, there was very little tubulin, almost no $\beta$-actin and no detectable cytokeratin 8. Cytoskeletal elements (microfilaments, intermediate filaments, microtubules and vinblastine-induced microtubular aggregates) would, therefore, seem to selectively escape autophagic sequestration, probably for mechanical reasons. Our previous results indicate that neither microtubules nor microfilaments are required for autophagy [48]; if intermediate (cytokeratin) filaments are involved, they apparently do not remain firmly associated with the autophagosomes.

This work was generously supported by the Research Council of Norway and by the Norwegian Cancer Society. The excellent technical assistance provided by Lilian Lindbergsengen and Lena Haugland Moen is gratefully acknowledged. We also thank Professor Brian Storrie (State University, Blacksburg, VA, U.S.A.) and Professor Trond Berg (University of Oslo, Oslo, Norway) for particularly helpful discussions during the study.

\section{REFERENCES}

1 Seglen, P. 0. and Bohley, P. (1992) Experientia 48, 158-172

2 Ericsson, J. L. E. (1969) Exp. Cell Res. 56, 393-405

3 Seglen, P. 0. (1987) in Lysosomes: Their Role in Protein Breakdown (Glaumann, H. and Ballard, F. J., eds.), pp. 369-414, Academic Press, London

4 Punnonen, E.-L., Pihakaski, K., Mattila, K., Lounatmaa, K. and Hirsimäki, P. (1989) Cell Tissue Res. 258, 269-276

5 Furuno, K., Ishikawa, T., Akasaki, K., Lee, S., Nishimura, Y., Tsuji, H., Himeno, M. and Kato, K. (1990) Exp. Cell Res. 189, 261-268

6 Fengsrud, M., Roos, N., Berg, T., Liou, W., Slot, J. W. and Seglen, P. O. (1995) Exp. Cell Res. 221, 504-519

7 Gordon, P. B. and Seglen, P. O. (1988) Biochem. Biophys. Res. Commun. 151, 40-47

8 Dunn, W. A. (1990) J. Cell Biol. 110, 1935-1945

9 Strømhaug, P. E. and Seglen, P. O. (1993) Biochem. J. 291, 115-121

10 Rabouille, C., Strous, G. J., Crapo, J. D., Geuze, H. J. and Slot, J. W. (1993) J. Cell Biol. 120, 897-908

11 Holen, I., Gordon, P. B. and Seglen, P. 0. (1991) Biomed. Biochim. Acta 50, 389-392
12 Gordon, P. B., Holen, I., Fosse, M., Røtnes, S. and Seglen, P. O. (1993) J. Biol. Chem. 268, 26107-26112

13 Holen, I., Gordon, P. B. and Seglen, P. O. (1993) Eur. J. Biochem. 215, 113-122

14 Holen, I., Strømhaug, P. E., Gordon, P. B., Fengsrud, M., Berg, T. 0. and Seglen, P. 0. (1995) J. Biol. Chem. 270, 12823-12831

15 Ogier-Denis, E., Couvineau, A., Maoret, J. J., Houri, J. J., Bauvy, C., De Stefanis, D., Isidoro, C., Laburthe, M. and Codogno, P. (1995) J. Biol. Chem. 270, 13-16

16 Fellinger, E. and Réz, G. (1990) Eur. J. Cell Biol. 51, 220-228

17 Gray, R. H., Sokol, M., Brabec, R. K. and Brabec, M. J. (1981) Exp. Mol. Pathol. 34, 72-86

18 Marzella, L., Ahlberg, J. and Glaumann, H. (1982) J. Cell Biol. 93, 144-154

19 Furuno, K., Ishikawa, T. and Kato, K. (1982) J. Biochem. (Tokyo) 91, 1943-1950

20 Seglen, P. 0. (1976) Methods Cell Biol. 13, 29-83

21 Berg, T. 0., Strømhaug, P. E., Berg, T. and Seglen, P. O. (1994) Eur. J. Biochem. 221, 595-602

22 Holen, I., Gordon, P. B., Strømhaug, P. E., Berg, T. O., Fengsrud, M., Brech, A., Roos, N., Berg. T. and Seglen, P. 0. (1995) Biochem. J. 311, 317-326

23 Gordon, P. B. and Seglen, P. 0. (1982) Exp. Cell Res. 142, 1-14

24 Kopitz, J., Kisen, G. Ø., Gordon, P. B., Bohley, P. and Seglen, P. 0. (1990) J. Cell Biol. 111, 941-953

25 Jadot, M., Colmant, C., Wattiaux-De Coninck, S. and Wattiaux, R. (1984) Biochem. J. 219, 965-970

26 Bergmeyer, H. U. and Berndt, E. (1974) Methoden der Enzymatischen Analyse, Verlag Chemie, Weinheim

27 Ames, B. N. (1966) Methods Enzymol. 8, 115-118

28 Cooperstein, S. J. and Lazarow, A. (1951) J. Biol. Chem. 89, 665-670

29 Beaufay, H., Amar-Costesec, A., Feytmans, E., Thinès-Sempoux, D., Wibo, M., Robbi, M. and Berthet, J. (1974) J. Cell Biol. 61, 188-200

30 Seglen, P. O. and Gordon, P. B. (1982) Proc. Natl. Acad. Sci. U.S.A. 79, 1889-1892

31 Slot, J. W. and Geuze, H. J. (1985) Eur. J. Cell Biol. 38, 87-93

32 Kovács, A. L., Grinde, B. and Seglen, P. 0. (1981) Exp. Cell Res. 133, 431-436

33 Kovács, A. L., Reith, A. and Seglen, P. 0. (1982) Exp. Cell Res. 137, 191-201

34 Strømhaug, P. E., Berg, T. O., Berg, K. and Seglen, P. O. (1997) Biochem. J. 321, 217-225

35 Bloom, G. S. and Brashear, T. A. (1989) J. Biol. Chem. 264, 16083-16092

36 Mandel, R., Ryser, H. J.-P., Ghani, F., Wu, M. and Peak, D. (1993) Proc. Natl. Acad. Sci. U.S.A. 90, 4112-4116

37 Dunn, W. A. (1990) J. Cell Biol. 110, 1923-1933

38 Ueno, T., Muno, D. and Kominami, E. (1991) J. Biol. Chem. 266, 18995-18999

39 Yokota, S., Himeno, M. and Kato, K. (1994) Acta Histochem. Cytochem. 27, 573-579

40 Reunanen, H. and Hirsimäki, P. (1983) Histochemistry 79, 59-67

41 Reunanen, H., Punnonen, E.-L. and Hirsimäki, P. (1985) Histochemistry 83, 513-517

42 Yamamoto, A., Masaki, R., Fukui, Y. and Tashiro, Y. (1990) J. Histochem. Cytochem. 38, 1571-1581

43 Baba, M., Osumi, M. and Ohsumi, Y. (1995) Cell Struct. Funct. 20, 465-471

44 Purhonen, P., Pursiainen, K. and Reunanen, H. (1997) Eur. J. Cell Biol. 74, 63-67

45 Mu, F.-T., Callaghan, J. M., Steele-Mortimer, O., Stenmark, H., Parton, R. G., Campbell, P. L., McCluskey, J., Yeo, J.-P., Tock, E. P. C. and Toh, B.-H. (1995) J. Biol. Chem. 270, 13503-13511

46 Weigel, P. H. and Oka, J. A. (1984) J. Biol. Chem. 259, 1150-1154

47 Berg, T. O., Fengsrud, M., Strømhaug, P. E., Berg, T. and Seglen, P. 0. (1998) J. Biol. Chem. 273, 21883-21892

48 Blankson, H., Holen, I. and Seglen, P. 0. (1995) Exp. Cell Res. 218, 522-530 